\title{
Period of dominance of the ovulatory follicle influences embryo quality in lactating dairy cows
}

\author{
Ronaldo L A Cerri ${ }^{1,2}$, Heloísa M Rutigliano ${ }^{1}$, Ricardo C Chebel $^{1}$ and José E P Santos ${ }^{2}$ \\ ${ }^{1}$ School of Veterinary Medicine, University of California, Davis, California 95616, USA and ${ }^{2}$ Department of Animal \\ Sciences, University of Florida, Gainesville, Florida 32611, USA
}

Correspondence should be addressed to J E P Santos; Email: jepsantos@ufl.edu

\begin{abstract}
Length of dominance of the ovulatory follicle and exposure to oestradiol $\left(\mathrm{OE}_{2}\right)$ during proestrus can affect fertility. Lactating cows had their oestrous cycle pre-synchronized and were subjected to one of the four synchronization treatments. Cows in the oestrus detection (OD) treatment received $\mathrm{GnRH}$ on day 6 of the oestrous cycle, $\mathrm{PGF}_{2 \alpha} 7$ days later, and were inseminated at detected oestrus. The remaining cows were subjected to the Ovsynch (OVS) protocol (day $0 \mathrm{GnRH}$, day $7 \mathrm{PGF}_{2 \alpha}$, day 9 GnRH, and timed artificial insemination (AI) 12 h later) starting on day 3 (OVS3) or day 6 (OVS6 and OVS6E) of the oestrous cycle. Cows in the OVS6E treatment received an injection of $0.5 \mathrm{mg}$ oestradiol cypionate $36 \mathrm{~h}$ before AI. Ovaries were examined by ultrasonography and blood was sampled for progesterone and $\mathrm{OE}_{2}$ concentrations. Uteri were flushed 6 days after $\mathrm{Al}$ and recovered embryos-oocytes evaluated. Diameter of the ovulatory follicle at Al differed $(P<0.01)$ among treatments, and it was the largest for OVS3 cows, which also had extended $(P<0.01)$ length of follicular dominance. During proestrus, OD and OVS6E cows had increased $(P<0.01) O E_{2}$ concentrations. Fertilization was not altered by treatments, and maximum fertilization was achieved when the number of accessory spermatozoa was $>7$. Proportions of viable embryos in relation to embryos and embryos-oocytes recovered were smaller for OVS3 cows $(P<0.01)$ than the other treatments, and embryos from OVS3 cows also had fewer $(P<0.01)$ blastomeres and tended $(P=0.09)$ to have a lower proportion of live blastomeres. Extending the period of follicle dominance did not alter fertilization but reduced $(P<0.001)$ embryo quality. Embryo quality was compromised even when the dominance of the ovulatory follicle was extended by only 1.5 days.
\end{abstract}

Reproduction (2009) 137 813-823

\section{Introduction}

High-producing lactating dairy cows have greater incidence of two waves of follicle growth during the oestrous cycle compared with growing heifers that are more likely to have three follicular waves (Savio et al. 1988). The interval from follicle emergence to oestrus, which is $\sim 3.5$ days greater for cows with two follicular waves than for those with three follicular waves (Bleach et al. 2004), has been associated with conception rates (Townson et al. 2002, Bleach et al. 2004). Cows inseminated after spontaneous display of oestrus had a linear reduction in conception rates as the interval from follicular emergence to oestrus increased (Bleach et al. 2004). This reduced fertility observed following periods of prolonged follicle dominance is associated with compromised oocyte quality (Revah \& Butler 1996) and embryonic development (Ahmad et al. 1995), although most of those studies used extremely prolonged periods of dominance that are unlikely to occur spontaneously.

Studies using the Ovsynch (OVS) protocol (Pursley et al. 1995) as a platform to synchronize follicle wave emergence, corpus luteum $(\mathrm{CL})$ regression and ovulation have shown that cows that ovulated to the first $\mathrm{GnRH}$ injection were more likely to ovulate the pre-ovulatory follicle after the second $\mathrm{GnRH}$ injection of the protocol (Vasconcelos et al. 1999, Rutigliano et al. 2008). Furthermore, ovulation to the first $\mathrm{GnRH}$ of the OVS programme increased conception rates (Chebel et al. 2006, Rutigliano et al. 2008). Therefore, ovulation to the first GnRH injection of the OVS protocol can improve fertility by increasing synchronization of ovulation near artificial insemination (Al), but could also cause the ovulation of a follicle with shorter dominance that might benefit fertilization and embryo quality. Some have suggested that implementation of timed Al programmes have coincided with increased detection of pregnancy losses in dairy cattle (Lucy 2001), although the risk of pregnancy loss seemed to be unaltered by inseminating cows following detection of oestrus or at fixed time (Santos et al. 2004). Whether synchronization programmes for $\mathrm{Al}$ using timed $\mathrm{Al}$ or insemination following detection of a synchronized oestrus affect fertilization and early embryonic development remains unknown. 
Lactating dairy cows have lower concentrations of gonadal steroid hormones compared with non-lactating dairy cows and growing heifers (Sangsritavong et al. 2002, Sartori et al. 2004). Because hepatic blood flow is correlated positively with feed and energy intakes (Reynolds et al. 2003), it has been hypothesized that the greater feed intake in high-producing dairy cows could affect metabolism and concentrations of progesterone and oestradiol $\left(\mathrm{OE}_{2}\right)$. In fact, changes in steroid hormone concentrations have been related to acute changes in liver blood flow following feed consumption (Sangsritavong et al. 2002). Reductions in peri-ovulatory $\mathrm{OE}_{2}$ concentrations might compromise spermatozoa transport in the female tract (Hawk 1983) and oviductal oocyte transport (Orihuela \& Croxatto 2001). Therefore, it is plausible to speculate that supplementation with $\mathrm{OE}_{2}$ during a synchronization protocol that might limit follicular $\mathrm{OE}_{2}$ production could improve fertilization. This may be particularly important in high-producing dairy cows that have inherently low concentrations during proestrus (Wiltbank et al. 2006). When lactating dairy cows were supplemented with oestradiol cypionate during proestrus, conception rates increased compared with non-supplemented cows (Cerri et al. 2004).

The objectives of the present study were to determine the effects of timing of initiation of the synchronization protocol (day 3 or day 6 of the oestrous cycle), which would alter the length of dominance of the ovulatory follicle, and $\mathrm{OE}_{2}$ supplementation on $\mathrm{OE}_{2}$ and progesterone concentrations, ovarian responses to the hormonal treatments, fertilization rate and embryo quality. An additional objective was to determine, whether insemination following a synchronized oestrus or at fixed time altered fertilization and embryo quality.

\section{Results}

The mean $( \pm$ s.D.) and median lactation number did not differ $(P>0.20)$ among treatments and were $2.45 \pm 1.37$ and 2.0 respectively. Similarly, the mean ( \pm S.E.M.) and median body condition score (BCS) on the day of study enrolment was not different $(P>0.50)$ among treatments and was respectively $2.80 \pm 0.31$ and 2.75 . The proportion of cows classified as cyclic before the initiation of the synchronization protocols was not $(P=0.87)$ different among treatments and averaged $83.9 \%$ (Table 1). The number of cows flushed during the study was 313, being 64, 83, 87 and 79 cows in oestrus detection (OD), OVS3, OVS6 and OVS6E respectively. The remaining cows included in the study were not flushed because of lack of oestrus display in the OD group, lack of ovulation to the last GnRH injection of the OVS, or cows that left the study before Al. There were 10 cows with double ovulation following $\mathrm{Al}$ and no difference $(P=0.88)$ was observed among treatments $(\mathrm{OD}=3 ; \mathrm{OVS} 3=1 ; \mathrm{OVS6}=3$ and OVS6E $=3)$. Only five out of the 10 cows with double ovulations yielded two embryos oocytes from the same cow $(\mathrm{OD}=1 ; \mathrm{OVS} 3=1$; $\mathrm{OVS} 6=2$ and OVS6E $=1$ ).

\section{Ovarian structures and responses to the OVS protocol}

Diameter of the dominant follicle in OVS3 was reduced $(P<0.001)$ at first $\mathrm{GnRH}$ injection of the synchronization protocol and differed from OD, OVS6 and OVS6E (Table 1). The proportion of cows that ovulated to the first GnRH injection of the synchronization protocol and started a new follicular wave was decreased $(P<0.001)$ in the OVS3 compared with OD, OVS6 and OVS6E. Complete luteolysis was similar $(P=0.70)$ among treatments and averaged $95.2 \%$. Treatment affected $(P<0.01)$ the diameter of the pre-ovulatory follicle near the time of $\mathrm{Al}$, and OVS3 cows had the largest follicle diameter, followed by OD and then OVS6 and OVS6E. Ovulation to the second GnRH injection of the OVS was similar $(P=0.78)$ among OVS3, OVS6 and OVS6E and averaged $87.7 \%$. Although ovulation to the second GnRH was similar among OVS treatments,

Table 1 Effect of treatment on proportion of cyclic cows, and ovarian structures and responses to the synchronization protocols.

\begin{tabular}{|c|c|c|c|c|}
\hline & \multicolumn{4}{|c|}{ Treatment } \\
\hline & OD & OVS3 & OvS6 & OVS6E \\
\hline Cows $(n)$ & 118 & 90 & 99 & 89 \\
\hline Cyclic cows (\%) & 85.5 & 83.1 & 86.7 & 82.0 \\
\hline DF at 1 st $\mathrm{GnRH}(\mathrm{mm} \pm$ s.E.M. $)$ & $14.2 \pm 0.4^{*,+}$ & $9.5 \pm 0.4^{\ddagger}$ & $15.4 \pm 0.4^{*}$ & $15.0 \pm 0.4^{*}$ \\
\hline Ovulation to 1 st GnRH (\%) & $81.2 *$ & $7.1^{+}$ & $88.6^{*}$ & $88.9^{*}$ \\
\hline CL regression $(\%)$ & 94.5 & 93.2 & 96.7 & 96.3 \\
\hline DF near $\mathrm{Al}(\mathrm{mm} \pm$ S.E.M.) & $19.7 \pm 0.3^{\dagger}$ & $20.7 \pm 0.4^{*}$ & $18.1 \pm 0.4^{\ddagger}$ & $17.7 \pm 0.4^{\ddagger}$ \\
\hline Ovulation to 2 nd $\mathrm{GnRH}(\%)$ & - & 86.7 & 87.9 & 88.6 \\
\hline Oestrous detection (\%) & 58.8 & - & - & - \\
\hline $\mathrm{CL}$ on day 6 after $\mathrm{Al}(\mathrm{mm} \pm$ S.E.M.) & $24.6 \pm 0.3^{*,+}$ & $25.3 \pm 0.3^{*}$ & $23.7 \pm 0.3^{+, \neq}$ & $23.1 \pm 0.3^{\neq}$ \\
\hline Dominance length (days \pm s.E.M.) & $7.1 \pm 0.2^{\dagger}$ & $8.0 \pm 0.2 *$ & $5.8 \pm 0.2^{\ddagger}$ & $5.7 \pm 0.2^{\ddagger}$ \\
\hline
\end{tabular}

${ }^{*,+, \pm}$ Superscripts in the same row differ $(P<0.001)$. OD, cows inseminated at oestrous detection; OVS3, cows starting the Ovsynch on day 3 of the oestrous cycle; OVS6, cows starting the Ovsynch on day 6 of the oestrous cycle; OVS6E, similar to OVS6 with an additional 0.5 mg of oestradiol cypionate $36 \mathrm{~h}$ before $\mathrm{Al}$; DF, dominant follicle diameter; $\mathrm{CL}$, corpus luteum; $\mathrm{Al}$, artificial insemination. 
despite major differences in ovulation to the initial $\mathrm{GnRH}$, cows that did not ovulate to the first GnRH had reduced $(P<0.01)$ ovulation to the final $\mathrm{GnRH}$ of the OVS protocols (77.0 vs $95.8 \%$ ).

OD for the OD treatment was $58.8 \%$ in the 7 days following $\mathrm{PGF}_{2 \alpha,}$ and $96.4 \%$ of the cows in oestrus ovulated within $48 \mathrm{~h}$ of oestrus. The mean ( \pm s.D.) interval from $\mathrm{PGF}_{2 \alpha}$ injection to oestrus was $3.7 \pm 1.2$ days. Distribution of observed oestruses varied from 1.5 to 7 days after the $\mathrm{PGF}_{2 \alpha}$ injection with $74.3 \%$ of the cows displaying oestrus between 2.5 and 4.0 days after the $\mathrm{PGF}_{2 \alpha}$ injection. The $\mathrm{CL}$ diameter 6 days after Al was greater $(P<0.01)$ in OVS3 compared with OVS6 and OVS6E. Cows in OD also had greater $(P=0.04) \mathrm{CL}$ diameter 6 days after Al than OVS6E cows. The length of dominance of the ovulatory follicle differed $(P<0.01)$ among treatments, and OVS3 cows had the longest dominance, followed by OD, and then OVS6 and OVS6E, but the latter two treatments did not differ.

\section{Progesterone and $\mathrm{OE}_{2}$ concentrations}

Progesterone concentrations at the first $\mathrm{GnRH}$ of the synchronization treatments differed $(P<0.001)$ and were lower for OVS3 $(0.8 \pm 0.1 \mathrm{ng} / \mathrm{ml})$ than the other treatments (Fig. 1). Concentrations were similar $(P>0.46)$ for OD, OVS6 and OVS6E $(1.7 \pm 0.1,1.6 \pm 0.1$ and $1.6 \pm 0.1 \mathrm{ng} / \mathrm{ml}$ respectively). Similarly, concentrations of progesterone differed $(P<0.01)$ on the day of $\mathrm{PGF}_{2 \alpha}$ and cows in OVS3 had lower concentrations $(3.1 \pm 0.2 \mathrm{ng} / \mathrm{ml})$ than cows in OD, OVS6, OVS6E $(3.9 \pm 0.2,4.2 \pm 0.2$ and $3.8 \pm 0.2 \mathrm{ng} / \mathrm{ml}$ respectively). Progesterone concentration near $\mathrm{Al}$ was similar $(P=0.13)$ among treatments and averaged $0.3 \pm 0.1$ $\mathrm{ng} / \mathrm{ml}$. Differences in progesterone concentrations were observed on day 6 after $\mathrm{Al}$, and concentration for cows in OVS6E $(1.6 \pm 0.1 \mathrm{ng} / \mathrm{ml})$ was lower $(P=0.02)$ and tended to be lower $(P=0.09)$ than those in OD $(2.1 \pm 0.1 \mathrm{ng} / \mathrm{ml})$ and OVS3 cows $(2.0 \pm 0.1 \mathrm{ng} / \mathrm{ml})$ respectively; however,

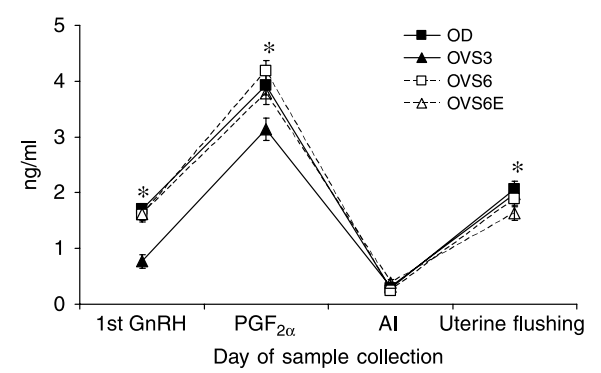

Figure 1 Plasma concentrations of progesterone during the synchronization treatments and on the day of uterine flushing. Within each time point, ${ }^{*}$ denotes difference among treatments $(P<0.05)$. The values are mean \pm S.E.M. concentrations. Al, artificial insemination; OD, cows inseminated at oestrous detection; OVS3, cows starting the Ovsynch on day 3 of the oestrous cycle; OVS6, cows starting the Ovsynch on day 6 of the oestrous cycle; OVS6E, similar to OVS6 with an additional $0.5 \mathrm{mg}$ of oestradiol cypionate $36 \mathrm{~h}$ before Al. concentration of progesterone on day 6 after Al did not differ between OVS6 $(1.90 \pm 0.1 \mathrm{ng} / \mathrm{ml})$ and the remaining treatments.

$\mathrm{OE}_{2}$ concentration at $48 \mathrm{~h}$ after the $\mathrm{PGF}_{2 \alpha}$ injection of the synchronization was greater $(P<0.01)$ for OVS6E than all other treatments (Fig. 2). Cows in OVS3 and OVS6 had similar concentrations of $\mathrm{OE}_{2}$, but they were both greater $(P<0.05)$ than OD. At $72 \mathrm{~h}$ after the $\mathrm{PGF}_{2 \alpha}$ injection, $\mathrm{OE}_{2}$ concentration was greater $(P<0.01)$ for OD than all other treatments, and OVS6E had greater $(P=0.05)$ concentration than OVS3 and OVS6. Because some OD cows were observed in oestrus after $72 \mathrm{~h}$ following $\mathrm{PGF}_{2 \alpha}$, an additional analysis was performed for concentrations of $\mathrm{OE}_{2}$ near the time of $\mathrm{Al}$ (Fig. 2). Cows in OD and OVS6E had similar $(P=0.14) \mathrm{OE}_{2}$ concentrations, but both were greater $(P<0.01)$ than OVS3 and OVS6 treatments.

\section{Embryo-oocyte evaluation}

The number of embryos-oocytes recovered relative to the number of $\mathrm{CL}$ was not $(P=0.15)$ different among treatments and averaged $53.7 \%$ (Table 2). Fertilization rate averaged $86.3 \%$, and it did not differ $(P=0.96)$ among treatments. The critical number of accessory spermatozoa that resulted in the highest sensitivity and specificity for fertilization was $>4$ (Fig. 3). Using this cut-off, the sensitivity and specificity were respectively,
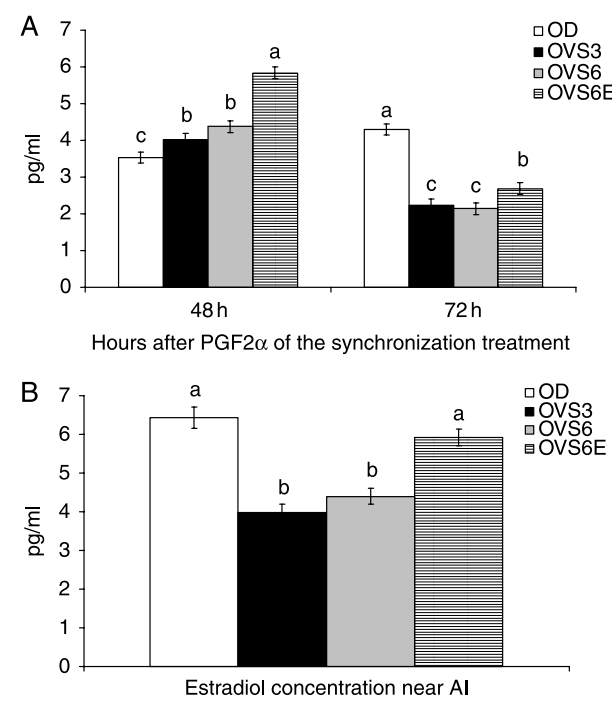

Figure 2 (A) plasma concentrations of oestradiol at 48 and $72 \mathrm{~h}$ after $\mathrm{PGF}_{2 \alpha}$ of the synchronization treatments. ${ }^{\mathrm{a}, \mathrm{b}, \mathrm{c}}$ Bars having different letters differ $(P<0.01)$. Effect of treatment $(P=0.01)$, time $(P=0.001)$ and treatment by time interaction $(P=0.01)$. (B) plasma concentrations of oestradiol near the time of artificial insemination from all treatments. ${ }^{\mathrm{a}, \mathrm{b}}$ Bars having different letters differ $(P<0.01)$. The values are mean \pm S.E.M. Concentrations. OD, cows inseminated at oestrous detection; OVS3, cows starting the Ovsynch on day 3 of the oestrous cycle; OVS6, cows starting the Ovsynch on day 6 of the oestrous cycle; OVS6E, similar to OVS6 with an additional $0.5 \mathrm{mg}$ of oestradiol cypionate $36 \mathrm{~h}$ before $\mathrm{Al}$. 
Table 2 Effect of treatment on recovery, fertilization and embryo quality parameters of collected embryos-oocytes.

\begin{tabular}{|c|c|c|c|c|}
\hline & \multicolumn{4}{|c|}{ Treatment } \\
\hline & OD & OVS3 & OVS6 & OVS6E \\
\hline Cows $(n)$ & 118 & 90 & 99 & 89 \\
\hline Embryos-oocytes $(n)$ & 41 & 40 & 43 & 44 \\
\hline Recovery (\%) & 64.1 & 48.2 & 49.4 & 55.7 \\
\hline \multicolumn{5}{|l|}{ Embryos-oocytes } \\
\hline Fertilization (\%) & 85.4 & 85.0 & 86.0 & 88.6 \\
\hline Embryos grades 1 and $2(\%)$ & $61.0^{*}$ & $40.0^{+}$ & $72.0^{*}$ & $65.9^{*}$ \\
\hline Degenerated $(\%)$ & $21.9^{\neq, \S}$ & $25.0^{\ddagger}$ & $9.3^{\|}$ & $11.4^{\S, \|}$ \\
\hline Degenerated-unfertilized (\%) & $36.6^{\ddagger, \S}$ & $40.0^{\ddagger}$ & $23.3^{\S}$ & $22.7^{\S}$ \\
\hline \multicolumn{5}{|l|}{ Embryos } \\
\hline Embryos $(n)$ & 35 & 34 & 37 & 39 \\
\hline Embryos grades 1 and 2 (\%) & $71.4^{*}$ & $47.0^{+}$ & $83.7^{*}$ & $74.3^{*}$ \\
\hline Degenerated $(\%)$ & $25.7^{\ddagger}$ & $29.4^{\ddagger}$ & $10.8^{\S}$ & $12.8^{\S}$ \\
\hline \multicolumn{5}{|l|}{ Blastomeres } \\
\hline Mean士s.E.M. & $43.5 \pm 4.4^{*}$ & $29.6 \pm 4.4^{+}$ & $40.9 \pm 4.0^{*}$ & $45.2 \pm 3.7^{*}$ \\
\hline Median $(n)$ & $49^{+}$ & $32 *$ & $42^{+}$ & $45^{+}$ \\
\hline Live $(\%)$ & $91.4^{+}$ & $91.6^{+}$ & $97.9^{*}$ & $98.2^{*}$ \\
\hline \multicolumn{5}{|l|}{ Accessory spermatozoa } \\
\hline Mean \pm S.E.M. & $26.2 \pm 6.5^{\neq}$ & $22.5 \pm 6.2^{\ddagger, \S}$ & $12.2 \pm 6.3^{\S}$ & $15.7 \pm 6.1^{\neq, s}$ \\
\hline Median $(n)$ & 10.5 & 8.0 & 7.0 & 8.5 \\
\hline Embryos-oocytes with $\geq 1$ (\%) & $95.0^{*}$ & $89.7 *$ & $74.4^{+}$ & $95.4 *$ \\
\hline Embryos-oocytes with $>4(\%)$ & 73.0 & 62.9 & 57.5 & 59.5 \\
\hline
\end{tabular}

${ }^{*}{ }^{+}$Superscripts in the same row $\operatorname{differ}(P<0.05)$. ${ }^{\ddagger, \$, l}$ Superscripts in the same row differ $(P<0.10)$. OD, cows inseminated at oestrous detection; OVS3, cows starting the Ovsynch on day 3 of the oestrous cycle; OVS6, cows starting the Ovsynch on day 6 of the oestrous cycle; OVS6E, similar to OVS6 with an additional $0.5 \mathrm{mg}$ of oestradiol cypionate $36 \mathrm{~h}$ before Al.

$71.3(95 \%$ confidence interval $(\mathrm{Cl})=63.2-78.6)$ and $91.3 \%(95 \% \mathrm{Cl}=71.9-98.7)$, and the area under the curve was $0.87(95 \% \mathrm{Cl}=0.81-0.92 ; P<0.001)$. Onehundred percent fertilization was observed when the number of accessory spermatozoa was $>7$. Using this cut-off resulted in fertilization rates of $100 \%(86 / 86)$ and $71.3 \%(57 / 80)$ for embryos-oocytes with $>7$ and $\leq 7$ accessory spermatozoa respectively $(P<0.001)$.

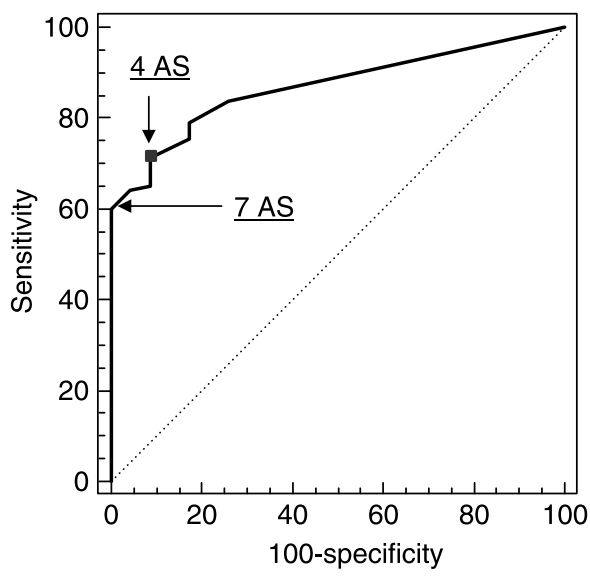

Figure 3 Receiver operating characteristic curve for number of accessory spermatozoa and fertilization rate. The square in the curve illustrates the optimal sensitivity and specificity relationship defined by the analysis; the cut-off number of accessory spermatozoa was 4 . The sensitivity and specificity were $71.3(95 \% \mathrm{Cl}=63.2-78.6)$ and $91.3 \%$ $(95 \% \mathrm{Cl}=71.9-98.7)$. The area under the curve was $0.87(95 \% \mathrm{Cl}=$ $0.81-0.92 ; P<0.001)$. For $100 \%$ fertilization, the cut-off was $>7$ accessory spermatozoa. AS, accessory spermatozoa.
Relative to embryos-oocytes, the proportion of embryos graded as 1 and 2 was less $(P<0.02)$ for OVS3 than the remaining treatments (Table 2). Similarly, the proportion of degenerated embryos was the greatest for OVS3, but it tended to differ $(P<0.10)$ only from OVS6 and OVS6E. When data from both unfertilized and degenerate were evaluated together, cows in OVS3 tended $(P<0.10)$ to have a greater proportion of nonviable structures than OVS6 and OVS6E. In relation to embryos, cows in OVS3 had a lower $(P<0.05)$ proportion of high-quality embryos than OD, OVS6 and OVS6E. Likewise, cows in OD and OVS3 tended to have $(P<0.10)$ greater proportions of degenerated embryos than OVS6 and OVS6E. The mean and median number of blastomeres differed $(P<0.01)$ among treatments, and they were both lower for OVS3 than all other treatments. Similarly, cows in OVS3 had a lower $(P<0.05)$ proportion of live blastomeres than the remaining treatments. Median number of accessory spermatozoa was similar among treatments, but mean number tended to differ $(P<0.10)$ because cows in OD had more accessory spermatozoa than OVS6. In addition, OVS6 had a lower $(P<0.05)$ proportion of embryos-oocytes with $\geq 1$ accessory spermatozoon than the remaining treatments. Although, treatment did not influence fertilization despite altering the mean number of accessory speramatozoa and the proportion of embryos-oocytes with $\geq 1$ spermatozoon, it was observed that embryos had increased $(P<0.01)$ median number of accessory spermatozoa than oocytes (10.0 vs 1.0). Furthermore, only $65.2 \%$ of the oocytes had $\geq 1$ 
accessory spermatozoon, whereas $92.3 \%$ of the embryos had $\geq 1$ accessory spermatozoon $(P<0.01)$. Although OVS6 had a reduced proportion of embryos-oocytes with $\geq 1$ accessory spermatozoon compared with the remaining treatments, the same was not observed for the proportion of embryos-oocytes with $>4$ accessory spermatozoa (Table 2), which was the cut-off for maximum sensitivity and specificity for fertilization.

Because the experimental design aimed to reduce ovulation to the first GnRH in OVS3 and to have maximum ovulation in OD, OVS6 and OVS6E treatments (i.e. OVS3, cows not ovulating; OD, OVS6 and OVS6E, cows ovulating), additional analyses were performed for cows that followed these expected responses for the respective treatments (Table 3). Recovery and fertilization rate were similar among treatments. With respect to embryos-oocytes, the proportion of grades 1 and 2 embryos was lower $(P<0.05)$ for OVS3 than the remaining treatments. Degenerated embryos were more prevalent $(P<0.05)$ in OD and OVS3 than OVS6, whereas OD tended to have $(P=0.08)$ more degenerated embryos than OVS6E. The proportion of non-viable embryos-oocytes tended $(P<0.10)$ to be greater for cows inseminated following OD and OVS3 than those in OVS6 and OVS6E. Relative to embryos, the proportion of grades 1 and 2 were lower $(P<0.05)$ for OVS3 than the other treatments. Cows in OD and OVS3 had $(P<0.05)$ greater proportions of degenerated embryos than those in OVS6; they also tended to have $(P=0.08)$ greater proportions of degenerated embryos than OVS6E. The mean and median number of blastomeres were both lower $(P<0.05)$ for OVS3 than all other treatments. Similarly, OVS3 had a lower $(P<0.05)$ proportion of live blastomeres than the remaining treatments. Cows in OD had a greater $(P=0.03)$ mean number of accessory spermatozoa compared with OVS6, but they did not differ from OVS3 and OVS6E. Similarly, the median number of accessory spermatozoa tended $(P<0.10)$ to be greater for OD than OVS3 and OVS6. The proportion of embryos-oocytes with $>1$ accessory spermatozoon was lower $(P<0.05)$ for OVS6 than the other treatments.

Although treatments influenced embryo quality and concentrations of progesterone and $\mathrm{OE}_{2}$, no relationship was observed between proportion of embryos graded as 1 and 2 and $\mathrm{OE}_{2}$ concentrations at $48 \mathrm{~h}$ after $\mathrm{PGF}_{2 \alpha}$ or near Al. At $48 \mathrm{~h}$ after $\mathrm{PGF}_{2 \alpha,}$, concentrations of $\mathrm{OE}_{2}$ were $4.7 \pm 0.2$ and $4.7 \pm 0.3 \mathrm{pg} / \mathrm{ml}$ for cows with and without embryos graded 1 and 2 respectively. At Al, concentrations of $\mathrm{OE}_{2}$ were $3.6 \pm 0.2$ and $3.4 \pm 0.3 \mathrm{pg} / \mathrm{ml}$ for cows with and without embryos graded 1 and 2 respectively. Similarly, progesterone concentrations on day 6 after $\mathrm{Al}$ in cows that ovulated within $48 \mathrm{~h}$ of Al did not differ between cows with and without embryos graded 1 and 2 and they were $1.8 \pm 0.1$ and $1.9 \pm 0.1 \mathrm{ng} / \mathrm{ml}$ respectively.

The distribution of embryos according to grade quality and fertilization shifted with altering the period of follicle dominance (Fig. 4). Follicles with shorter length of dominance yielded a greater proportion of grades 1 and

Table 3 Effect of treatment on recovery, fertilization, and quality parameters of collected embryos-oocytes from cows in the OD, OVS6 and OVS6E treatments that ovulated and cows from the OVS3 treatment that did not ovulate in response to the first GnRH injection of the synchronization protocol.

\begin{tabular}{|c|c|c|c|c|}
\hline & \multicolumn{4}{|c|}{ Treatment } \\
\hline & OD & OVS3 & OVS6 & OVS6E \\
\hline Cows $(n)$ & 99 & 84 & 90 & 80 \\
\hline Embryos-oocytes $(n)$ & 37 & 36 & 40 & 42 \\
\hline Recovery (\%) & 64.9 & 46.7 & 48.2 & 55.3 \\
\hline \multicolumn{5}{|l|}{ Embryos-oocytes } \\
\hline Fertilization (\%) & 89.2 & 83.3 & 87.5 & 90.5 \\
\hline Embryos grades 1 and $2(\%)$ & $64.9^{*}$ & $38.9^{\dagger}$ & $77.5^{*}$ & $69.0^{*}$ \\
\hline Degenerated (\%) & $24.2^{*, \neq}$ & $22.2^{*}$ & $5.0^{\dagger}$ & $9.5^{\S}$ \\
\hline Degenerated-unfertilized (\%) & $35.1^{\neq}$ & $38.9^{\ddagger}$ & $17.5^{\S}$ & $19.1^{\S}$ \\
\hline \multicolumn{5}{|l|}{ Embryos } \\
\hline Embryos $(n)$ & 33 & 30 & 35 & 38 \\
\hline Embryos grades 1 and $2(\%)$ & $72.7^{*}$ & $46.7^{+}$ & $88.6^{*}$ & $76.3 *$ \\
\hline Degenerated (\%) & $27.3^{*}$ & $26.7^{*}$ & $5.7^{+}$ & $10.5^{*,+}$ \\
\hline \multicolumn{5}{|l|}{ Blastomeres } \\
\hline Mean \pm s.E.M. & $43.8 \pm 4.0^{*}$ & $28.0 \pm 4.2^{+}$ & $41.3 \pm 3.9^{*}$ & $45.7 \pm 3.7^{*}$ \\
\hline Median $(n)$ & $49^{+}$ & $32 *$ & $43^{+}$ & $45^{+}$ \\
\hline Live $(\%)$ & $91.7^{\dagger}$ & $89.8^{\dagger}$ & $97.9 *$ & $98.1^{*}$ \\
\hline \multicolumn{5}{|l|}{ Accessory spermatozoa } \\
\hline Mean \pm S.E.M. & $28.4 \pm 6.9^{*}$ & $22.8 \pm 6.8^{*,+}$ & $10.2 \pm 6.7^{\dagger}$ & $15.5 \pm 6.4^{*+}+$ \\
\hline Median $(n)$ & $11.0^{\ddagger}$ & $7.0^{\S}$ & $6.5^{\S}$ & $8.5^{\ddagger, \S}$ \\
\hline Embryos-oocytes with $\geq 1$ (\%) & $94.6^{*}$ & $88.6^{*}$ & $72.5^{+}$ & $95.2^{*}$ \\
\hline Embryos-oocytes with > $4(\%)$ & 71.4 & 61.8 & 56.3 & 56.4 \\
\hline
\end{tabular}

${ }^{*}, \mathrm{t}$ Superscripts in the same row differ $(P<0.05) .{ }^{\ddagger}$ S Superscripts in the same row differ $(P<0.10)$. OD, cows inseminated at oestrous detection; OVS3, cows starting the Ovsynch on day 3 of the oestrous cycle; OVS6, cows starting the Ovsynch on day 6 of the oestrous cycle; OVS6E, similar to OVS6 with an additional $0.5 \mathrm{mg}$ of oestradiol cypionate $36 \mathrm{~h}$ before Al. 


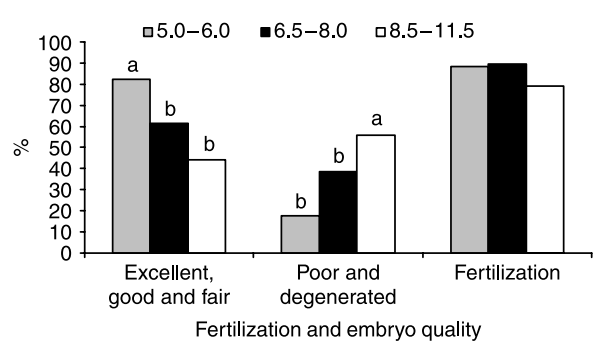

Figure 4 Distribution of frequency of embryos according to grade quality and of oocyte fertilization (IETS 1998) relative to period of dominance of the ovulatory follicle. Fertilization remained unaltered $(P=0.27)$, but embryo quality declined $(P<0.001)$ with increasing period of dominance. ${ }^{\mathrm{a}, \mathrm{b}}$ Bars having different letters differ $(P<0.01)$.

2 embryos, whereas cows with a longer period of dominance had increased proportion of poor quality and degenerated embryos. Fertilization rate remained unaffected by the period of dominance.

\section{Discussion}

The present study demonstrated that reproductive programmes that extend the period of follicle dominance influence embryo quality in lactating dairy cows. Follicles from cows in OVS3, which had a longer period of dominance than those from cows in OVS6 and OVS6E, resulted in embryos of reduced quality. Furthermore, embryos from cows in OVS3 had fewer blastomeres and a lower proportion of live blastomeres than embryos from cows in OVS6 and OVS6E. Surprisingly, cows inseminated on oestrus had a greater proportion of non-viable embryos and their embryos had a reduced proportion of live blastomeres compared with cows in OVS6 and OVS6E. Cows in OD had an ovulatory follicle with 1.4 days of dominance longer than those in the OVS6 and OVS6E treatments, suggesting that small increases in the length of follicular dominance compromise embryo quality. Despite treatments, the proportion of viable embryos declined, and that of degenerated embryos and oocytes increased as dominance was extended.

The increased proportion of degenerated embryos with increased period of follicle dominance might explain the reductions in fertility of lactating dairy cows observed when dominance is extended spontaneously (Townson et al. 2002, Bleach et al. 2004), or of heifers induced to have persistent follicles (Schmitt et al. 1996). It is interesting to note that, when cows ovulated to the first $\mathrm{GnRH}$ of the synchronization treatments, those in OD had a greater proportion of degenerated embryos and embryos with a smaller proportion of live cells than cows receiving timed $\mathrm{Al}$ in OVS6 and OVS6E. Wiltbank et al. (2006) suggested that a potential mechanism reducing fertility of high-producing dairy cows is the reduced concentrations of steroids as a result of increased hepatic clearance. The increased hepatic metabolism may require that follicles develop longer to produce sufficient $\mathrm{OE}_{2}$ to induce oestrus and ovulation, which might compromise fertility. In support, it was observed that cows inseminated in oestrus had longer follicle dominance and increased degenerated embryos in the present study. Therefore, a slight extension in dominance can decrease embryo quality and fertility in cows that come naturally in oestrus. Previously, prolonged follicle dominance was implicated in reduced oocyte and embryo viability (Ahmad et al. 1995, Revah \& Butler 1996), and reduced pregnancy rate (Schmitt et al. 1996); however, in those studies, follicles were induced to become persistent by subluteal concentrations of progesterone. Furthermore, Mihm et al. (1999) reported that extending emergence to ovulation to 12 days resulted in oocytes that reached at least metaphase I, thereby characterizing premature resumption of meiosis, which is expected to compromise subsequent embryo development. Although these studies (Ahmad et al. 1995, Revah \& Butler 1996, Mihm et al. 1999) demonstrated deleterious effects of prolonged dominance on the oocyte and embryo, the models used are unlikely to be replicated in cows inseminated following oestrus or when timed $\mathrm{Al}$ programmes are properly implemented.

Fertilization was not altered by synchronization protocol or changes in length of dominance of the preovulatory follicle. Consequently, decreased fertility associated with extended dominance of the ovulatory follicle was not caused by alterations in the mechanisms related to oocyte fertilization. Although median number of accessory spermatozoa did not differ among treatments, cows in the OVS6 had embryos-oocytes with reduced number of accessory spermatozoa and proportion of embryos-oocytes with $\geq 1$ accessory spermatozoon. It is possible that changes in accessory spermatozoa might be related to decreased $\mathrm{OE}_{2}$ concentrations near $\mathrm{Al}$ in the OVS6 cows. $\mathrm{OE}_{2}$ is important for uterine motility and spermatozoa transport (Hawk 1983). It was initially hypothesized that increased concentration of $\mathrm{OE}_{2}$ during proestrus in the OVS protocol would enhance spermatozoa transport and fertilization. Although cows with increased $\mathrm{OE}_{2}$ concentration during proestrus had a greater number of accessory spermatozoa, particularly in the OD treatment, this improvement did not translate into a better fertilization rate. Embryos had increased numbers of accessory spermatozoa and a greater proportion of them had $\geq 1$ accessory spermatozoon than oocytes. The number of accessory spermatozoa with the combination of the highest sensitivity (detection of unfertilized oocytes) and specificity (detection of fertilized oocytes) for fertilization was 4 , but the number of accessory spermatozoa resulting in $100 \%$ specificity, i.e. $100 \%$ fertilization was $>7$. Previous reports observed a positive correlation between number of accessory spermatozoa and fertilization rate in cows (Dejarnette 
et al. 1992, Nadir et al. 1993). The cut-off number of seven accessory spermatozoa demonstrates that maximum fertilization in lactating dairy cows can be achieved with a relatively small number of spermatozoa reaching the oocyte.

As expected, ovulation to the first $\mathrm{GnRH}$ injection of the synchronization protocols differed among treatments and caused the expected changes in the length of dominance of the ovulatory follicle. Follicles of cows on day 3 of the oestrous cycle, as in the first GnRH of OVS3, probably had not undergone deviation and acquired $\mathrm{LH}$ receptors in the granulosa cells (Bao et al. 1997), making them incapable to respond to an LH surge and ovulate (Fortune et al. 2001). Consequently, fewer OVS3 cows had a new follicular wave recruited, thereby extending follicle growth in $\sim 2.3$ days compared with OVS6 and OVS6E cows. Although this resulted in older and larger follicles for OVS3, it did not alter ovulation to the final $\mathrm{GnRH}$ in cows receiving timed Al. Others (Vasconcelos et al. 1999, Rutigliano et al. 2008) observed that cows that did not ovulate to the first GnRH had reduced ovulation to the final GnRH of the OVS protocol. Therefore, decreased fertility observed in cows that do not ovulate to the initial GnRH of the OVS protocol (Chebel et al. 2006) may be caused by the reduced synchronization of ovulation when $\mathrm{Al}$ is performed, in addition to extension of the period of follicle dominance (Bleach et al. 2004).

Progesterone concentration at the first $\mathrm{GnRH}$ injection of the synchronization protocols was less for OVS3, which was expected because cows in the OVS3 started the synchronization during metestrus, whereas OD, OVS6 and OVS6E started during early diestrus. Furthermore, progesterone concentration at the $\mathrm{PGF}_{2 \alpha}$ injection was also reduced in OVS3 cows probably because they were in an earlier stage of the oestrous cycle. Moreover, fewer OVS3 cows responded to the first GnRH and, thus, did not form an accessory $\mathrm{CL}$ when $\mathrm{PGF}_{2 \alpha}$ was injected. In fact, the mean number of CL in the OVS3 treatment was 1.0 as opposed to 1.9 in the other treatments (data not shown). Progesterone concentration was greater in OD and OVS3 treatments compared with OVS6E on day 6 after Al. Both treatments, OD and OVS3, ovulated larger follicles than OVS6 and OVS6E cows and later developed a larger $\mathrm{CL}$ that probably had a greater steroidogenic capacity. This agrees with a previous observation showing greater progesterone concentration on day 7 of the oestrous cycle when cows ovulated larger follicles (Vasconcelos et al. 2001). $\mathrm{OE}_{2}$ concentration at $48 \mathrm{~h}$ after the $\mathrm{PGF}_{2 \alpha}$ injection was greater in OVS6E cows likely because of the treatment with oestradiol cypionate $24 \mathrm{~h}$ earlier. All treatments, but OD, had a decrease in $\mathrm{OE}_{2}$ concentration at $72 \mathrm{~h}$ after the $\mathrm{PGF}_{2 \alpha}$ injection. For cows receiving the OVS protocol, the blood sample taken at $72 \mathrm{~h}$ after the $\mathrm{PGF}_{2 \alpha}$ was collected after the final $\mathrm{GnRH}$ injection of the protocol that induced an LH surge. Consequently, LH caused down regulation of aromatase mRNA in granulosa cells (Fitzpatrick et al. 1997) and cessation of $\mathrm{OE}_{2}$ synthesis by the pre-ovulatory follicle. On the other hand, most cows in the OD treatment were observed in oestrus $72 \mathrm{~h}$ after the $\mathrm{PGF}_{2 \alpha}$ and, therefore, still had an oestrogenactive pre-ovulatory follicle.

The lack of an effect of increased $\mathrm{OE}_{2}$ concentration near Al from either an endogenous (OD) or an exogenous (OVS6E) source on fertilization suggests that beneficial effects of $\mathrm{OE}_{2}$ supplementation on conception rate observed previously (Cerri et al. 2004) were probably caused by post-fertilization processes. Mann \& Lamming (2000) demonstrated that ovariectomized cows exposed to greater concentrations of exogenous $\mathrm{OE}_{2}$ during an induced proestrus had reduced concentrations of $\mathrm{PGF}_{2 \alpha}$ metabolite after an oxytocin challenge in late diestrus of the subsequent simulated oestrous cycle. Attenuating $\mathrm{PGF}_{2 \alpha}$ release during the period of maternal recognition of pregnancy could improve the embryo survival in cows supplemented with $\mathrm{OE}_{2}$. Nevertheless, the potential improvement in pregnancy in dairy cows to $\mathrm{OE}_{2}$ supplementation is probably not mediated by increased fertilization. Furthermore, timed insemination following the OVS protocol does not limit fertilization when compared with cows inseminated at synchronized oestrus.

The deleterious effects on embryo quality observed in OD and OVS3 compared with OVS6 and OVS6E occurred despite similar or even greater progesterone concentrations 6 days after Al. Mann \& Lamming (2001) suggested that the rise in progesterone concentration shortly after oestrus was pivotal for embryo development, and Lopes et al. (2007) observed a greater likelihood for pregnancy for cows with greater progesterone concentrations after day 5 of the oestrous cycle. However, both studies did not confirm occurrence of ovulation after $\mathrm{Al}$, which would compromise both luteal function and pregnancy (Rutigliano et al. 2008). Concentrations of $\mathrm{OE}_{2}$ during proestrus and progesterone 6 days after Al were similar between cows categorized as having embryos or not as grades 1 and 2 . Therefore, the role of $\mathrm{OE}_{2}$ at proestrus or the progesterone rise during early diestrus that influences pregnancy could be more related to effects on the uterus and not necessarily on early embryo development. Recently, Pereira et al. (2009) observed no positive effect of progesterone on embryo development at days 8 and 12 using an in vitro culture system with granulosa or oviductal epithelial cells. It is possible that differences in embryo quality relative to ovarian steroid concentrations in the peri-ovulatory period and early diestrus occur only past day 6 of development. Collectively, these data demonstrate that length of dominance of the ovulatory follicle is more important to embryo development until day 6 after insemination than the steroidal endocrine milieu in the peri-ovulatory period. 
In conclusion, reducing the period of follicle dominance by optimizing the ovulatory response to the initial $\mathrm{GnRH}$ injection of the synchronization protocol improved early embryo development. Reduction in embryo quality was observed even when concurrent extension of follicle dominance was of only 1.5 to 2 days. Furthermore, if embryo quality influences pregnancy in lactating dairy cows, then optimization of fertility should be observed when dominance of the ovulatory follicle is restricted to 5-6 days. It is noteworthy that cows inseminated following a synchronized oestrus had increased proportion of degenerated embryos, which was associated with longer dominance because of the increased interval from $\mathrm{CL}$ regression to oestrus and AI. Fertilization and embryo quality on day 6 after $\mathrm{Al}$ were not associated with $\mathrm{OE}_{2}$ concentrations during proestrus, or with progesterone concentrations on day 6 after Al. These data indicate that period of dominance is probably more important for early embryo quality in high producing lactating dairy cows than the endocrine steroidal milieu in which the ovulatory follicle develops. Moreover, these data also indicate that properly implemented timed $\mathrm{Al}$ programmes result in similar or better quality embryos than cows inseminated at synchronized oestrus. Therefore, it is plausible that high producing cows with extended interval between follicle deviation to oestrus have reduced fertility because embryo quality is compromised when dominance of the ovulatory follicle is increased by as few as 1.5 days.

\section{Materials and Methods}

\section{Animals, housing and diets}

The University of California, Davis Institutional Animal Care and Use Committee approved all procedures in this study. Three hundred and ninety six (107 primiparous and 289 multiparous) lactating Holstein cows (Bos taurus taurus) from one farm located in the San Joaquim valley of California were enrolled in the present study. The number of lactating cows in the herd during the study was $\sim 900$ and the 305 day $3.5 \%$ fatcorrected milk rolling herd average was $11700 \mathrm{~kg} / \mathrm{cow}$. Animals were housed in free-stall barns equipped with fans and sprinklers that were automatically turned on when the temperature reached $26.7{ }^{\circ} \mathrm{C}$. All cows were fed with the same diet as a total mixed ration twice daily to meet or exceed the dietary requirements for lactating cows weighing $680 \mathrm{~kg}$, consuming $24 \mathrm{~kg}$ of dry matter and producing $45 \mathrm{~kg}$ of milk containing $3.5 \%$ fat and $3.1 \%$ true protein in the first 70 days of lactation (National Research Council 2001).

All cows had their body condition scored at $30 \pm 3$ and $60 \pm 3$ days in milk (DIM) according to Ferguson et al. (1994), and only cows with $2.50 \geq$ BCS $\leq 3.75$ at $30 \pm 3$ DIM were enrolled in the experiment. Cows were classified according to the average BCS measured at $30 \pm 3$ and $60 \pm 3$ DIM as having a low BCS if the average was $\leq 2.75$ or moderate BCS if the average was $>2.75$. Cows diagnosed with any evident health disorder (displacement of the abomasum, lameness, uterine infection and uterine adhesions) were not enrolled in the study.

\section{Treatments and $A I$}

Starting at $30 \pm 3$ DIM, all cows had their ovulation synchronized with the OVS protocol (Pursley et al. 1995) and a controlled internal drug releasing (CIDR; EAZI Breed, Pfizer Animal Health, New York, NY, USA) as follows: day 30, $100 \mu \mathrm{g}$ of GnRH (gonadorelin diacetate tetrahydrate, Merial Ltd, Iselin, $\mathrm{NJ}$, USA) and a CIDR insert; day 37, an injection of $25 \mathrm{mg}$ of $\mathrm{PGF}_{2 \alpha}$ (dinoprost tromethamine, Pfizer Animal Health) concurrent with the removal of the CIDR insert; day 39, a second injection of $\mathrm{GnRH}$. The second GnRH injection of the presynchronization protocol was considered to be day 0 of the oestrous cycle and of the study. Only cows that had a synchronized ovulation based on disappearance of the dominant follicle within $48 \mathrm{~h}$ of the final $\mathrm{GnRH}$ of the presynchronization were enrolled in the study.

Cows were randomly assigned to one of the four treatments (Fig. 5). OD ( $n=118)$ received an injection of $100 \mu \mathrm{g} \mathrm{GnRH}$ on day 6, an injection of $25 \mathrm{mg} \mathrm{PGF}_{2 \alpha}$ on day 13 , and were inseminated after detected in oestrus. Cows in OD were observed for visual signs of oestrus twice daily $(\mathrm{am} / \mathrm{pm})$ and $\mathrm{AI}$ was performed when cows were first detected in oestrus. The remaining cows were submitted to one of the OVS protocols OVS3 $(n=90)$, OVS6 $(n=99)$ or OVS6E $(n=89)$. In all OVS treatments, cows received $\mathrm{Al}$ at fixed time $12 \mathrm{~h}$ after the last $\mathrm{GnRH}$ injection of the protocols. Cows assigned to the OVS3 treatment started the OVS protocol on day 3 and those assigned to the OVS6 and OVS6E treatment started the OVS protocol on day 6 of the oestrous cycle. Cows in the OVS6E received an additional $0.5 \mathrm{mg}$ injection of oestradiol cypionate (ECP, Pfizer Animal Health) $36 \mathrm{~h}$ before Al.

The same person inseminated all cows with semen from a single sire of proven fertility and high expected relative conception rate from field inseminations in lactating cows.

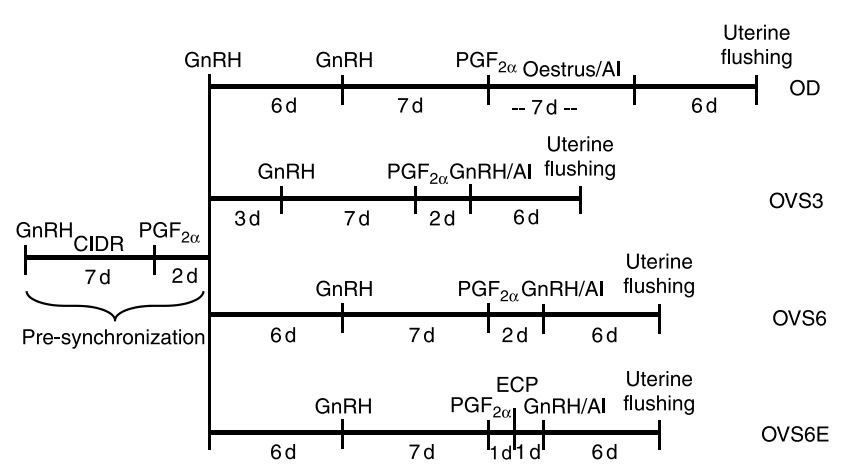

Figure 5 Diagram of the ovulation synchronization protocols used for each treatment. CIDR, controlled internal drug release containing $1.38 \mathrm{~g}$ of progesterone; $\mathrm{OD}$, cows inseminated at oestrous detection; ECP, oestradiol cypionate; Oestrus/Al, oestrus observation and artificial insemination; $\mathrm{GnRH} / \mathrm{Al}$, GnRH injection and artificial insemination 12 h later; OVS3, cows starting the Ovsynch on day 3 of the oestrous cycle; OVS6, cows starting the Ovsynch on day 6 of the oestrous cycle; OVS6E, similar to OVS6 with an additional $0.5 \mathrm{mg}$ of ECP $36 \mathrm{~h}$ before Al. 


\section{Blood samples and $\mathrm{OE}_{2}$ and progesterone analysis}

Approximately, $7 \mathrm{ml}$ blood was collected by puncture of the median coccygeal vein or artery utilizing evacuated tubes (Vacutainer systems, Becton \& Dickinson, Rutherford, NJ, USA) containing $\mathrm{K}_{2}$ EDTA. Samples were immediately placed in ice and transported to laboratory within $5 \mathrm{~h}$ and centrifuged at $2000 \mathrm{~g}$ for $15 \mathrm{~min}$ for separation of plasma. Plasma was harvested and subsequently frozen at $-25^{\circ} \mathrm{C}$ until later analyses of progesterone and $\mathrm{OE}_{2}$ concentrations.

Blood samples collected at the $\mathrm{GnRH}$ and $\mathrm{PGF}_{2 \alpha}$ injections of the pre-synchronization protocol $(30 \pm 3$ and $37 \pm 3$ DIM) were used to determine cyclic status based on progesterone concentration. Samples were collected immediately before CIDR insertion and $30 \mathrm{~min}$ after CIDR removal on the days of $\mathrm{GnRH}$ and $\mathrm{PGF}_{2 \alpha}$ injections respectively, to avoid increases in plasma progesterone caused by the supplemental progesterone from the intravaginal insert (Cerri et al. 2009). Cows with progesterone concentration $\geq 1.0 \mathrm{ng} / \mathrm{ml}$ in 1 of the two samples were classified as cyclic, whereas those with progesterone concentrations $<1.0 \mathrm{ng} / \mathrm{ml}$ in both samples were classified as anovular. Blood samples for the analysis of progesterone concentration were also collected concurrent with the hormonal treatments during the synchronization protocols $\left(\mathrm{GnRH}, \mathrm{PGF}_{2 \alpha}\right.$, and $48 \mathrm{~h}$ later) and 6 days after $\mathrm{Al}$ when embryo collection was performed. Plasma samples were analyzed in duplicates for progesterone concentration by an ELISA validated by Cerri et al. (2004). Each microplate contained the standards $0.1,0.2,0.5,1.0,2.0,5.0,10.0$ and $20.0 \mathrm{ng} / \mathrm{ml}$. The intra- and inter-assay coefficients of variation (CV) were 4.7 and $13.0 \%$ respectively. Cows with progesterone concentrations in plasma $\geq 1.0 \mathrm{ng} / \mathrm{ml}$ on the day of $\mathrm{PGF}_{2 \alpha}$ injection of synchronization treatments and then $<1.0 \mathrm{ng} / \mathrm{ml}$ $48 \mathrm{~h}$ later were classified as experiencing complete luteolysis.

$\mathrm{OE}_{2}$ concentration was analyzed in plasma samples collected at 48 and $72 \mathrm{~h}$ after the $\mathrm{PGF}_{2 \alpha}$ injection of the synchronization treatments in all cows. An additional blood sample was collected and plasma analyzed for $\mathrm{OE}_{2}$ at the time of $\mathrm{Al}$ in cows in the OD treatment when oestrus was detected after $72 \mathrm{~h}$ of the $\mathrm{PGF}_{2 \alpha}$ injection of the synchronization. Samples were analyzed in duplicates using a validated RIA (Kirby et al. 1997). Standards were 0.25, 0.50, 1.0, 2.5, 5.0, 7.5, 10.0 and $20.0 \mathrm{pg} / \mathrm{ml}$. The intra- and inter-assay CV were 10.2 and $13.2 \%$ respectively.

\section{Ovarian ultrasonography}

Cows had their ovaries examined by ultrasound (Aloka SSD-500, Aloka Co. Ltd, Wallingford, CT, USA) equipped with a $7.5 \mathrm{MHz}$ linear rectal transducer at every injection of the synchronization treatments and again $48 \mathrm{~h}$ later. For OD cows, an additional ultrasound examination was performed the day they were observed in oestrus. Ovaries were also examined by ultrasound on the day of embryo collection. Maps of the ovaries were drawn for each individual cow and size and position of follicles $\geq 5 \mathrm{~mm}$ in diameter and $\mathrm{CL}$ were recorded. Occurrence of ovulation within $48 \mathrm{~h}$ after each $\mathrm{GnRH}$ injection was characterized by the disappearance of a previously recorded follicle $\geq 10 \mathrm{~mm}$ in diameter. The length of dominance of the ovulatory follicle was defined by the period between the day of follicular deviation and OD or last GnRH of the OVS protocol (OVS3, OVS6, OVS6E). Follicular deviation was assumed to have occurred 3.5 days after the first $\mathrm{GnRH}$ of the synchronization treatment for cows that ovulated to that GnRH (Roche 2004). For cows that failed to ovulate to the first GnRH of the synchronization treatments, deviation was assumed to have occurred 3.5 days after the final GnRH of the pre-synchronization treatment, as all cows enrolled in the study had a synchronized ovulation after the presynchronization programme.

\section{Embryo-oocyte collection and evaluation}

Cows had their uteri flushed on day 6 after Al by a transcervical procedure using a silicon Foley catheter $(18 \mathrm{Fr}, 30 \mathrm{ml}$, $56 \mathrm{~cm}$; Minitube of America, Inc., Verona, WI, USA). The balloon of the catheter was placed $\sim 3 \mathrm{~cm}$ passing the external intercornual ligament of the uterine horn ipsilateral to the ovary bearing the CL. Approximately, $300 \mathrm{ml}$ of a flushing solution (ViGro complete flush solution, Bioniche Life Sciences Inc., Belleville, ON, Canada) was used for a single uterine horn. Embryos-oocytes collected were evaluated for fertilization and grade quality $(1=$ excellent and good; $2=$ fair; $3=$ poor and $4=$ degenerated; IETS 1998). Embryos were stained with $5 \mu \mathrm{g} / \mathrm{ml}$ propidium iodide (Sigma) to determine the number of nonviable blastomeres and then with $5 \mu \mathrm{g} / \mathrm{ml}$ Hoechst 33342 (Molecular Probes Inc., Eugene, OR, USA) to determine the number of accessory spermatozoa using epifluorescence microscopy (365 nm excitation, $>400 \mathrm{~nm}$ emission). The zona pellucida was then dissolved with a solution of $0.02 \mathrm{~N} \mathrm{HCl}$ in $0.1 \%$ Tween-20 (Sigma). The embryo was again stained with $5 \mu \mathrm{g} / \mathrm{ml}$ Hoechst 33342 and the blastomeres spread in a glass slide and counted using epifluorescence microscopy.

\section{Experimental design and statistical analysis}

The experimental design was randomized with incomplete blocks. Lactating Holstein cows were blocked at 30 \pm 3 DIM according to parity (primiparous or multiparous) and BCS (low or moderate) and, within each block, randomly assigned to one of the four treatments. More cows were enrolled in the OD treatment because it was expected that OD would be less than $80 \%$.

Dichotomous outcomes were evaluated by logistic regression using the LOGISTIC procedure of SAS (Statistical Analysis Software, SAS Institute Inc., Cary, NC, USA). Count data such as number of accessory spermatozoa and blastomeres were analyzed by the GENMOD procedure of SAS (Statistical Analysis Software, SAS Institute Inc.) using a Poisson distribution. The models included the effects of treatment, parity, cyclic status and average BCS.

Progesterone and $\mathrm{OE}_{2}$ concentrations were analyzed by ANOVA for repeated measures using the MIXED procedure of SAS (Statistical Analysis Software, SAS Institute Inc.). The covariance structure with the smallest Akaike's information criterion was used for measurements utilized in the MIXED model. The models included the effects of treatment, day of blood collection, interaction between treatment and day of blood collection, parity (primiparous and multiparous) and 
average BCS (low and moderate), with cow nested within treatment as the random error. For progesterone, analyses were performed separately for samples collected before and after $\mathrm{PGF}_{2 \alpha}$ injection during synchronization treatments.

Analysis of dominant follicle diameter was performed by ANOVA with the GLM procedure of SAS (Statistical Analysis Software, SAS Institute Inc.) with a model that included the effects of treatment, parity, cyclic status and average BCS.

Receiver operating characteristic (ROC), analysis using MedCalc version 9.5.1.0 (MedCalc software, Mariakerke, Belgium) was performed to determine the critical number of accessory spermatozoa to optimize fertilization based on sensitivity and specificity. The ROC curve analysis plots the sensitivity against the false positive fraction ( 1 - specificity) to detect the best combination of sensitivity and specificity for the number of accessory spermatozoa for fertilization, and the point closest to the left upper corner represents the best combination of them.

Differences with $P \leq 0.05$ were considered significant and from $0.05<P \leq 0.10$ were designated as tendency.

\section{Declaration of interest}

The authors declare that there is no conflict of interest that could be perceived as prejudicing the impartiality of the research reported.

\section{Funding}

This research was supported by grants from the National Research Initiative Competitive Grant Program from the US Department of Agriculture Cooperative State Research, Education, and Extension Service (grant no. 2004-35203-14137), Select Sires Inc, and the Center for Food Animal Health of the School of Veterinary Medicine, University of California Davis.

\section{Acknowledgements}

The authors wish to thank J M DeJarnette from Select Sires Inc. for donation of the semen. Our gratitude is also extended to Oscar Rodriguez and the staff of the Corcoran State Prison dairy in Corcoran, CA, USA.

\section{References}

Ahmad N, Schrick FN, Butcher RL \& Inskeep EK 1995 Effect of persistent follicles on early embryonic losses in beef cows. Biology of Reproduction 52 1129-1135.

Bao B, Garverick HA, Smith GW, Smith MF, Salfen BE \& Youngquist RS 1997 Changes in messenger RNA encoding $\mathrm{LH}$ receptor, cytochrome $\mathrm{P} 450$-side chain cleavage, and aromatase are associated with recruitment and selection of bovine ovarian follicles. Biology of Reproduction 56 1158-1169.

Bleach ECL, Glencross RG \& Knight PG 2004 Association between ovarian follicle development and pregnancy rates in dairy cows undergoing spontaneous oestrous cycle. Reproduction 127 621-629.

Cerri RLA, Santos JE, Juchem SO, Galvão KN \& Chebel RC 2004 Timed artificial insemination with estradiol cypionate or insemination at estrus in high-producing dairy cows. Journal of Dairy Science $\mathbf{8 7}$ 3704-3715.
Cerri RLA, Rutigliano HM, Bruno RGS \& Santos JEP 2009 Progesterone concentration, follicular development and induction of cyclicity in dairy cows receiving intravaginal progesterone inserts. Animal Reproduction Science 110 56-70.

Chebel RC, Santos JEP, Cerri RLA, Rutigliano HM \& Bruno RGS 2006 Reproduction in dairy cows following progesterone insert presynchronization and resynchronization protocols. Journal of Dairy Science $\mathbf{8 9}$ 4205-4219.

DeJarnette JM, Saacke RG, Bame J \& Vogler CJ 1992 Accessory sperm: their importance to fertility and embryo quality, and attempts to alter their numbers in artificially inseminated cattle. Journal of Animal Science $\mathbf{7 0}$ 484-491.

Ferguson JD, Galligan DT \& Thomsen N 1994 Principal descriptors of body condition score in Holstein cows. Journal of Dairy Science 77 2695-2703.

Fitzpatrick SL, Carlone DL, Robker RL \& Richards JS 1997 Expression of aromatase in the ovary: down-regulation of mRNA by the ovulatory luteinizing hormone surge. Steroids 62 197-206.

Fortune JE, Rivera GM, Evans ACO \& Turzillo AM 2001 Differentiation of dominant versus subordinate follicles in cattle. Biology of Reproduction 65 648-654.

Hawk HW 1983 Sperm survival and transport in the female reproductive tract. Journal of Dairy Science 66 2645-2660.

IETS 1998 Manual of the International Embryo Transfer Society, 3 edn. Savoy, IL: IETS

Kirby CJ, Smith MF, Keisler DH \& Lucy MC 1997 Follicular function in lactating dairy cows treated with sustained-release bovine somatotropin. Journal of Dairy Science $\mathbf{8 0} 273-285$.

Lopes AS, Butler ST, Gilbert RO \& Butler WR 2007 Relationship of preovulatory follicle size, estradiol concentration and season to pregnancy outcome in dairy cows. Animal Reproduction Science 99 34-43.

Lucy MC 2001 Reproductive loss in high-producing dairy cattle: where will it end? Journal of Dairy Science 84 1277-1293.

Mann GE \& Lamming GE 2000 The role of sub-optimal preovulatory oestradiol secretion in the aetiology of premature luteolysis during the short oestrous cycle in the cow. Animal Reproduction Science 64 $171-180$.

Mann GE \& Lamming GE 2001 Relationship between maternal endocrine environment, early embryo development and inhibition of the luteolytic mechanism in cows. Reproduction 121 175-180.

Mihm M, Curran N, Hyttel P, Knight PG, Boland MP \& Roche JF 1999 Effect of dominant follicle persistence on follicular fluid oestradiol and inhibin and on oocyte maturation in beef heifers. Journal of Reproduction and Fertility 116 293-304.

Nadir S, Saacke RG, Bame J, Mullins J \& Degelos S 1993 Effect of freezing semen and dosage of sperm on number of accessory sperm, fertility, and embryo quality in artificially inseminated cattle. Journal of Animal Science 71 199-204.

National Research Council 2001 Nutrient Requirements of Dairy Cattle, 7 edn. Washington, DC: National Academy Press.

Orihuela PA \& Croxatto HB 2001 Acceleration of oviductal transport of oocytes induced by estradiol in cycling rats is mediated by nongenomic stimulation of protein phosphorilation in the oviduct. Biology of Reproduction 65 1238-1245.

Pereira RM, Marques CC, Baptista MC, Vasques MI \& Horta AE 2009 Embryos and culture cells: a model for studying the effect of progesterone. Animal Reproduction Science 111 31-40.

Pursley JR, Mee MO \& Wiltbank MC 1995 Synchronization of ovulation in dairy cows using $\mathrm{PGF}_{2 \alpha}$ and GnRH. Theriogenology 44 915-923.

Revah I \& Butler WR 1996 Prolonged dominance of follicles and reduced viability of bovine oocytes. Journal of Reproduction and Fertility 106 339-347.

Reynolds CK, Aikman PC, Lupoli B, Humphries DJ \& Beever DE 2003 Splanchnic metabolism of dairy cows during the transition from late gestation through early lactation. Journal of Dairy Science 86 1201-1217.

Roche JF 2004 Follicular waves in cattle. Veterinary Research Communications 28 107-110.

Rutigliano HM, Lima FS, Cerri RLA, Greco LF, Vilela JM, Magalhães V, Silvestre FT, Thatcher WW \& Santos JEP 2008 Effects of method of presynchronization and source of selenium on uterine health and reproduction in dairy cows. Journal of Dairy Science $\mathbf{9 1}$ 3323-3336. 
Sangsritavong S, Combs DK, Sartori R, Armentano LE \& Wiltbank MC 2002 High feed intake increases liver blood flow and metabolism of progesterone and estradiol- $17 \beta$ in dairy cattle. Journal of Dairy Science 85 2831-2842.

Santos JE, Thatcher WW, Chebel RC, Cerri RL \& Galvão KN 2004 The effect of embryonic death rates in cattle on the efficacy of estrus synchronization programs. Animal Reproduction Science 82-83 513-535.

Sartori R, Haughian JM, Shaver RD, Rosa GJM \& Wiltbank MC 2004 Comparison of ovarian functions and circulating steroids in estrous cycles of Holstein heifers and lactation cows. Journal of Dairy Science $\mathbf{8 7}$ 905-920.

Savio JD, Keenan L, Boland MP \& Roche JF 1988 Pattern of growth of dominant follicles during the oestrous cycle of heifers. Journal of Reproduction and Fertility 83 663-671.

Schmitt EJP, Drost M, Diaz T, Roomes C \& Thatcher WW 1996 Effect of a gonadotropin-releasing hormone agonist on follicle recruitment and pregnancy rate in cattle. Journal of Animal Science 74 154-161.

Townson DH, Tsang PC, Butler WR, Frajblat M, Griel LC Jr, Johnson CJ, Milvae RA, Niksic GM \& Pate JL 2002 Relationship of fertility to ovarian follicular waves before breeding in dairy cows. Journal of Animal Science 80 1053-1058.
Vasconcelos JLM, Silcox RW, Rosa GJM, Pursley JR \& Wiltbank MC 1999 Synchronization rate, size of the ovulatory follicle, and pregnancy rate after synchronization of ovulation beginning on different days of the estrous cycle in lactating dairy cows. Theriogenology 15 1067-1078.

Vasconcelos JLM, Sartori R, Oliveira HN, Guenther JG \& Wiltbank MC 2001 Reduction in size of the ovulatory follicle reduces subsequent luteal size and pregnancy rate. Theriogenology 15 307-314.

Wiltbank MC, Lopez H, Sartori R, Sangsritavong S \& Gumen A 2006 Changes in reproductive physiology of lactating dairy cows due to elevated steroid metabolism. Theriogenology 65 17-29.

Received 2 June 2008

First decision 28 July 2008

Revised manuscript received 30 January 2009

Accepted 9 February 2009 